Matija Sakoman

Danko Ćorić

Tamara Aleksandrov Fabijanić

Saša Kovačić

https://doi.org/10.21278/TOF.44103

ISSN 1333-1124

eISSN 1849-1391

\title{
TRIBOLOGICAL PROPERTIES OF COATINGS APPLIED ON NEAR- NANO AND NANOSTRUCTURED WC-CO HARDMETALS BY USING PLASMA-ASSISTED CHEMICAL VAPOUR DEPOSITION TECHNIQUE
}

\begin{abstract}
Summary
Samples of nanostructured hardmetals were sintered as a substrate material by applying two different powder metallurgy processes. The starting powders had an average grain size from $95 \mathrm{~nm}$ to $150 \mathrm{~nm}$. The plasma-assisted chemical vapour deposition technique was used for the deposition of coatings and two coating systems, i.e. the $2 \mu \mathrm{m}$ titanium nitride and 3.8 $\mu \mathrm{m}$ titanium carbon nitride were produced. Scratch tests were conducted with an increasing load ranging from 5 to $200 \mathrm{~N}$. Critical normal loads of coating delamination during the scratch tests were registered. The sliding wear resistance was investigated with a ball-on-disc test. The ball-on-disc test showed that the porosity of the sintered product had the highest impact on the wear volume loss. Nanostructured hardmetals showed a great potential for application of plasma-assisted chemical Vapour deposition.
\end{abstract}

Key words: $\quad$ plasma-assisted chemical vapour deposition, titanium nitride, titanium carbon nitride, hardmetals, cemented carbides

\section{Introduction}

Hardmetals, also known as cemented carbides, have proven to be an optimal material in the cutting industry with respect to price and tool lifetime. Improvements in the mechanical properties, such as hardness, fracture toughness and, consequently, service lives of tools made of hardmetals are nowadays achieved with a decrease in the grain size to a nanoscale [1-3]. The main reason for seeking further improvements in sintering processes is to a achieve products without porosity applying the full density process. However, cheaper and porous tools that are subsequently coated still appear on the market and deterioration of such tools occurs much sooner, due to poor coating adhesion.

The extension of the tool life by reducing friction and wear is accomplished by applying thin hard coatings on the surface, provided that the used technology will result in layers that have satisfying coating adhesion [4-7]. 
M. Sakoman, D. Ćorić, T. Aleksandrov Fabijanić, S. Kovačić
Tribological Properties of Coatings Applied on Near-Nano and Nanostructured WC-Co Hardmetals by Using Plasma-Assisted Chemical Vapour Deposition Technique

As nanoscaled hardmetals are highly reactive, in both the sintering phase and the coating phase, very often microstructural defects, such as the $\eta$-phase, occur. The $\eta$-phase is a hard and brittle $\mathrm{Co}_{\mathrm{x}} \mathrm{W}_{\mathrm{y}} \mathrm{C}$ ternary compound, where $\mathrm{x}+\mathrm{y}=6\left(\mathrm{M}_{6} \mathrm{C}\right)$ or $12\left(\mathrm{M}_{12} \mathrm{C}\right)$, and $\mathrm{x}$ and $\mathrm{y}$ values range from 2 to 6 [8]. It occurs in tungsten carbide (WC)-cobalt (Co) hardmetals in two cases. The first case occurs as a result of inappropriate atmosphere regulation during sintering, specifically because of decarburizing reactions [9]. The second case occurs as a result of coating refractory films created on carbide substrates [10], specifically during the high-temperature chemical vapour deposition. In most cases the formation of the $\eta$-phase is undesirable because of the reduction in mechanical properties [11-16], but there have been cases in which the formation of the mentioned phase showed improvements in exploitation properties of special tools [11]. The influence of that phase on coating adhesion is yet to be determined.

According to new research results multilayer gradient coatings need to be used in order to achieve serious tool improvements in terms of heat dissipation [17] and a support layer for the upper coating with satisfactory properties is to be obtained [18]. Nitrides and carbides are the most common compounds used $[19,20]$. Combined chemical and mechanical loadings are still the main reasons for the failure of these new coating types. [21]. If adequately produced, these coatings provide significant improvements in hardness, toughness, oxidation and corrosion resistance [22]. In the literature [23-48], it is often reported that titanium nitride (TiN) as a bottom supporting layer is the base for a successful multilayer coating. As standalone coatings, TiN coatings are extensively used in tribological applications because of their high hardness, wear resistance and low friction coefficient [21]. However, for complex tribological applications layers such as TiN/TiCN, TiN/NbN, TiN/VN, TiN/AlN, TiN/CrN, TiN/ZrN, TiN/TiAlN, TiN/TiBN, TiN/CN and TiN/TaN are applied to hardmetals as well as cutting steels [23-48]. As the metal cutting industry is slowly scaling their cutting tools to nanograin sizes, these complex coating architectures are being developed on the tool surface on a daily basis, and scientists yet have to quantify the influence of the base material / coating combinations that result in significant improvements in properties.

For this reason, coating adhesion as well as dry sliding wear resistance are investigated on samples of nanostructured hardmetals coated with thin ceramic TiN and multilayer gradient titanium carbon nitride (TiCN) produced by plasma-assisted chemical vapour deposition technique. The aim was to study the potential of nanostructured hardmetals as substrate materials for plasma-assisted chemical vapour deposited (PACVD) coatings.

\section{Experimental procedure}

The starting WC powder containing grain growth inhibitors $\mathrm{Cr}_{3} \mathrm{C}_{2} / \mathrm{VC}$ was manufactured by H.C. Stark, Germany. The powders have an average grain size $\mathrm{d}_{\mathrm{BET}}$ in the range from $95 \mathrm{~nm}$ to $150 \mathrm{~nm}$ and a specific surface area (BET) in the range from $2.5 \mathrm{~m}^{2} / \mathrm{g}$ to $4.0 \mathrm{~m}^{2} / \mathrm{g}$. The Co powder used was HCP Co, produced by Umicore, Canada. It has a $\mathrm{d}_{\mathrm{BET}}$ of $210 \mathrm{~nm}$. The powders were mixed in a horizontal ball mill in a closed container containing nitrogen atmosphere for the purpose of the $\mathrm{WC}$ and Co homogenization. The prepared mixtures had different Co content for two WC grain sizes with different grain growth inhibitors, as presented in Table 1.

Table 1 Characteristics of the mixtures [49]

\begin{tabular}{cccccc}
\hline \multirow{2}{*}{ Mixture } & \multirow{2}{*}{ Powder } & $\begin{array}{c}\text { Grain size } \\
d_{\text {BET }}(\mathrm{nm})\end{array}$ & $\begin{array}{c}\text { Specific } \\
\text { surface }\left(\mathrm{m}^{2} / \mathrm{g}\right)\end{array}$ & GGI (wt \%) & \multirow{2}{*}{ Co (wt \%) } \\
\hline 1 & WC DN 4-0 & 95 & 3.92 & $0.41 \% \mathrm{VC}, 0.80 \% \mathrm{Cr}_{3} \mathrm{C}_{2}$ & 6 \\
\hline 2 & WC DN 2-5/1 & 150 & 2.57 & $0.26 \% \mathrm{VC}, 0.45 \% \mathrm{Cr}_{3} \mathrm{C}_{2}$ & 9 \\
\hline 3 & WC DN 2-5/1 & 150 & 2.57 & $0.26 \% \mathrm{VC}, 0.45 \% \mathrm{Cr}_{3} \mathrm{C}_{2}$ & 6 \\
\hline
\end{tabular}


Tribological Properties of Coatings Applied on Near-Nano and Nanostructured WC-Co Hardmetals by Using Plasma-Assisted Chemical Vapour Deposition Technique
M. Sakoman, D. Ćorić,

T. Aleksandrov Fabijanić,

S. Kovačić

After subsequent drying of the slurry and granulation, the samples were compacted. The compacting was performed by uniaxial die pressing at room temperature with a hydraulic press. The samples were sintered by two different powder metallurgy processes: the conventional liquid phase sintering in hydrogen and the hot isostatic pressing in one cycle, as shown in Table 2. Dimensional changes, i.e. the shrinkage of the samples during the sintering process, were in the range from $6 \%$ to $8 \%$. The samples with a $30 \mathrm{~mm}$ diameter and a thickness of $8 \mathrm{~mm}$ were measured after sintering.

Table 2 Sintering processes used to produce samples with different mixtures and the coating types deposited on the samples subsequently

\begin{tabular}{|c|c|c|c|}
\hline Mixture & Sintering process & Sample & Coating type \\
\hline 1 & \multirow{3}{*}{$\begin{array}{c}\text { sintering in } \\
\text { hydrogen }\end{array}$} & SV 1-1 & TiN \\
\cline { 3 - 3 } & & SV 2-1 & \\
\cline { 3 - 3 } & \multirow{3}{*}{ sinter-HIP } & SV 2-2 & multilayer gradient TiN-TiCN \\
\cline { 3 - 3 } & & SH 2-1 & TiN \\
\cline { 3 - 3 } & & SH 2-2 & \multirow{2}{*}{ multilayer gradient TiN-TiCN } \\
\cline { 3 - 3 } & & SH 3-2 & \\
\hline
\end{tabular}

The samples were prepared for the purposes of measuring the porosity and analysing the microstructure. For the latter purpose and for the purpose of measuring hardness the samples were poured into a Buehler pneumatic press at $143{ }^{\circ} \mathrm{C}$ into a polymeric material DuroFast and prepared metallographically in accordance with the recommendations for that type of material. Grinding was performed on a Buehler automatic polisher using a P120 sandpaper with water cooling at a speed of $300 \mathrm{rpm}$ and a pressure of $180 \mathrm{~N}$. After grinding and cleaning in ethyl alcohol, the samples were polished in three steps. In the first step, the polishing was performed on the surface with a MD Allegro grinding disc (Struers, Germany) and a diamond paste grain size $9 \mu \mathrm{m}$ at a speed of $150 \mathrm{rpm}$ and a pressure of $210 \mathrm{~N}$ for $5 \mathrm{~min}$. With the same force and at the same speed, the second polishing step was performed using a $3 \mu \mathrm{m}$ diamond paste and a Struers MD-Largo substrate for $10 \mathrm{~min}$. In the third step, a $3 \mu \mathrm{m}$ paste was polished on the DP-Dac substrate at $150 \mathrm{~N}$ for $8 \mathrm{~min}$. All polishing steps were performed at a speed of $150 \mathrm{rpm}$. Between the individual polishing steps, the samples were ultrasonically cleaned to avoid contamination of the substrates with the processing particles. The degree of porosity and uncombined carbon was determined by comparing the polished surface with photo micrographs according to the standard (ISO 4505:1978) [3, 49, 50]. Two to three second long etching in a Murakami reagent was carried out for the purpose of determining the presence of the $\eta$-phase. The analysis was performed using an optical microscope and a field emission scanning electron microscope (FESEM, manufacturer: Tescan, Czech Republic; type: MIRA/LMU). The measurement of the WC grain size, $d_{W C}$, was carried out by applying a conventional linear intercept method according to EN ISO 4499-2:2011. Vickers indentation was used for the determination of Vickers hardness HV30 of the substrate material.

The plasma-assisted chemical vapour deposition technique was used for applying coatings due to its lower coating temperature with respect to a classic CVD process in order to avoid further microstructural changes of highly reactive nanostructured hardmetals. Before deposition, the substrates were cleaned in ultrasonic baths of alkali solution and alcohol. The substrates were then coated in vacuum and the area was evacuated to a pressure of less than $10 \mathrm{~Pa}$, after which the sputtering of the substrates with $\mathrm{Ar}, \mathrm{N}_{2}$ and $\mathrm{H}_{2}$ ions was performed. All the substrates were positioned at the same height inside a PACVD Rübig furnace in order to achieve the same coating conditions. The temperature of the process was $500{ }^{\circ} \mathrm{C}$. TiN and multilayer gradient TiCN coatings were deposited on the substrate. As shown in Table 2, 
M. Sakoman, D. Ćorić,

T. Aleksandrov Fabijanić,

S. Kovačić
Tribological Properties of Coatings Applied on Near-Nano and Nanostructured WC-Co Hardmetals by Using Plasma-Assisted Chemical Vapour Deposition Technique

substrates SV 1-1, SV 2-1, and SH 2-1 containing TiN coating went through stages 1, 2, 3 and 6, while substrates SV 2-2, SH 2-2, SH 3-2 went through the entire 6 stages of the coating process. The coating parameters are shown in Table 3.

Table 3 PACVD TiN and multilayer gradient TiN-TiCN coating parameters

\begin{tabular}{r|cccccc}
\hline \multicolumn{1}{c|}{ Stage number } & 1 & 2 & 3 & 4 & 5 & 6 \\
\hline Stage description & Heating & Sputtering & TiN & $\begin{array}{c}\text { TiCN } \\
\text { transition }\end{array}$ & TiCN & Cooling \\
Stage duration (h) & 1 & 2 & 1.5 & 0.5 & 5.5 & 1 \\
Pressure (mbar) & 2 & 2 & 2 & 2 & 2 & 2 \\
Temperature $\left({ }^{\circ} \mathrm{C}\right)$ & $20-400$ & $420-500$ & 500 & 500 & 500 & $500-20$ \\
$\mathrm{H}_{2}$ flow (1/h) & 140 & 140 & 140 & 140 & 140 & 100 \\
Air flow (1/h) & 0 & 10 & 10 & 10 & 10 & 0 \\
$\mathrm{CH}_{4}$ flow (1/h) & 0 & 0 & 0 & 4.5 & 4.5 & 0 \\
TiCl 4 flow (1/h) & 0 & 0 & 3 & 3 & 3 & 0 \\
$\mathrm{~N}_{2}$ flow (1/h) & 0 & 23 & 15 & 15 & 15 & 0 \\
Voltage $(\mathrm{V})$ & 0 & $520-540$ & 490 & 490 & 490 & 0 \\
Plasma power $(\mathrm{W})$ & 0 & $900-1800$ & 1650 & 1400 & 1400 & 0 \\
\hline
\end{tabular}

The coating thickness of TiN and TiCN layers was determined by applying the ball crater test according to ISO EN 1071-2:2002. The equipment used was Tribotechnic calotester with a ball $\varnothing 25 \mathrm{~mm}$, made of $100 \mathrm{Cr} 6$ steel. The abrasive paste placed on the coated sample consisted of $1 \mu \mathrm{m}$ diamond paste suspended in ethanol. The ball rotated at $500 \mathrm{rpm}$ for a period of $30 \mathrm{~s}$ during which the coating layers and the substrate material became visible. After the test the spherical imprints were measured with an optical microscope to determine the dimensions of the abraded coating and to calculate the coating thickness. The instrumented nanoindentation test was used to determine the hardness of the coating. The indentation force was $50 \mathrm{mN}$, and the Vickers hardness was calculated as an average of ten measurements. Scratch tests were conducted by drawing a Rockwell $\mathrm{C}$ diamond indenter with a radius tip of $200 \mu \mathrm{m}$. The indenter was drawn across the sample surface using a linearly increasing load from 5 to $200 \mathrm{~N}$. During the scratch test, the friction force and acoustic emission signals were continuously measured. Critical normal loads (LC) were calculated as an average of three scratch marks and are defined as LC1 - the first micro cracking; LC2 - the first spallation (inside); LC3 - the first spallation (outside); LC4 - the first breakthrough; and LC5 - worn-out coating.

The wear test was carried out under reciprocating sliding conditions according to ASTM G99 with a ball-on-disc test on a linear reciprocating tribometer at room temperature. The test samples were loaded by an $\mathrm{Al}_{2} \mathrm{O}_{3}$ ball with a diameter of $6 \mathrm{~mm}$ with a force of $5 \mathrm{~N}$. The stroke, average sliding speed and frequency were $10 \mathrm{~mm}, 3.14 \mathrm{~cm} / \mathrm{s}$ and $1 \mathrm{~Hz}$, respectively. Wear volume loss was determined after the testing time of 2,000 cycles, corresponding to a total sliding distance of $10 \mathrm{~m}$, using the optical profilometry of the wear scar. Wear factor was calculated as a standardized wear volume with respect to the force and sliding path according to equation [44]:

$$
K_{W}=\frac{V}{F_{N} \cdot s}\left[\frac{\mathrm{mm}^{3}}{\mathrm{Nm}}\right]
$$

where $V$ represents the volume loss $\left(\mathrm{mm}^{3}\right), F_{N}$ the normal force on the pin $(\mathrm{N})$, and $s$ the sliding path $(\mathrm{m})$. 
Tribological Properties of Coatings Applied on Near-Nano and Nanostructured WC-Co Hardmetals by Using Plasma-Assisted Chemical Vapour Deposition Technique
M. Sakoman, D. Ćorić,

T. Aleksandrov Fabijanić,

S. Kovačić

\section{Results and discussion}

The characteristics of the consolidated near-nano and nanostructured hardmetals used as substrates are presented in Table 4.

Table 4 Characteristics of consolidated near-nano and nanostructured hardmetals used as substrates for coating

\begin{tabular}{|c|c|c|c|c|c|c|}
\hline \multirow{2}{*}{ Sample } & \multicolumn{3}{|c|}{ Porosity type } & \multirow{2}{*}{$\eta$-phase } & \multirow{2}{*}{$d_{\mathrm{WC}}(\mu \mathrm{m})$} & \multirow{2}{*}{ HV30 } \\
\hline & A & B & $\mathrm{C}$ & & & \\
\hline SV 1-1 & A04 & B02, B04 & $\mathrm{COO}$ & - & 0.170 & 2110 \\
\hline SV 2-1 & $\mathrm{A}<02, \mathrm{~A} 02$ & B00, B02 & $\mathrm{C} 00$ & - & 0.227 & 1863 \\
\hline SH 2-1 & $\mathrm{A} 00, \mathrm{~A}<02$ & B00 & $\mathrm{COO}$ & - & 0.191 & 1869 \\
\hline SV 2-2 & $\mathrm{A}<02, \mathrm{~A} 02$ & B00, B02 & $\mathrm{C} 00$ & - & 0.210 & 1900 \\
\hline SH 2-2 & $\mathrm{A} 00, \mathrm{~A}<02$ & B00 & $\mathrm{C} 00$ & - & 0.185 & 1897 \\
\hline SH 3-2 & $\mathrm{A}<02, \mathrm{~A} 02$ & B00 & $\mathrm{COO}$ & + & 0.200 & 2115 \\
\hline
\end{tabular}

Figures 1 a) and b) show the microstructure of samples SH 2-2 and SV 1-1, respectively. The degree of porosity of samples SV 2-1 and SV 2-2 sintered in hydrogen is A02, predominantly B00, partially B02, without uncombined carbon or $\eta$-phase. A high degree of porosity with pore sizes larger than $2 \mu \mathrm{m}$ was obtained in the case of sample SV 1-1 which was also sintered in hydrogen. The degree of porosity of the SV 1-1 sample ranges from A04 and B02 to B04 without uncombined carbon or $\eta$-phase. Additionally, small cracks occurred on sample SV 1-1 sintered in hydrogen, which resulted from one of the following technological operations: milling, waxing or granulation [3, 50]. Samples SH 2-1 and SH 2-2 consolidated by sintering and hot isostatic pressing achieved theoretical densities, while the SH 3-2 sample had almost theoretical density, amounting to $99.9 \%$. The degree of porosity of samples SH $2-$ 1 and SH 2-2 is A00, B00, without uncombined carbon or $\eta$-phase, while the degree of porosity of SH 3-2 is A02 B00 without uncombined carbon. The $\eta$-phase was detected on the surface of sample SH 3-2 consolidated by sintering and hot isostatic pressing [3, 50].

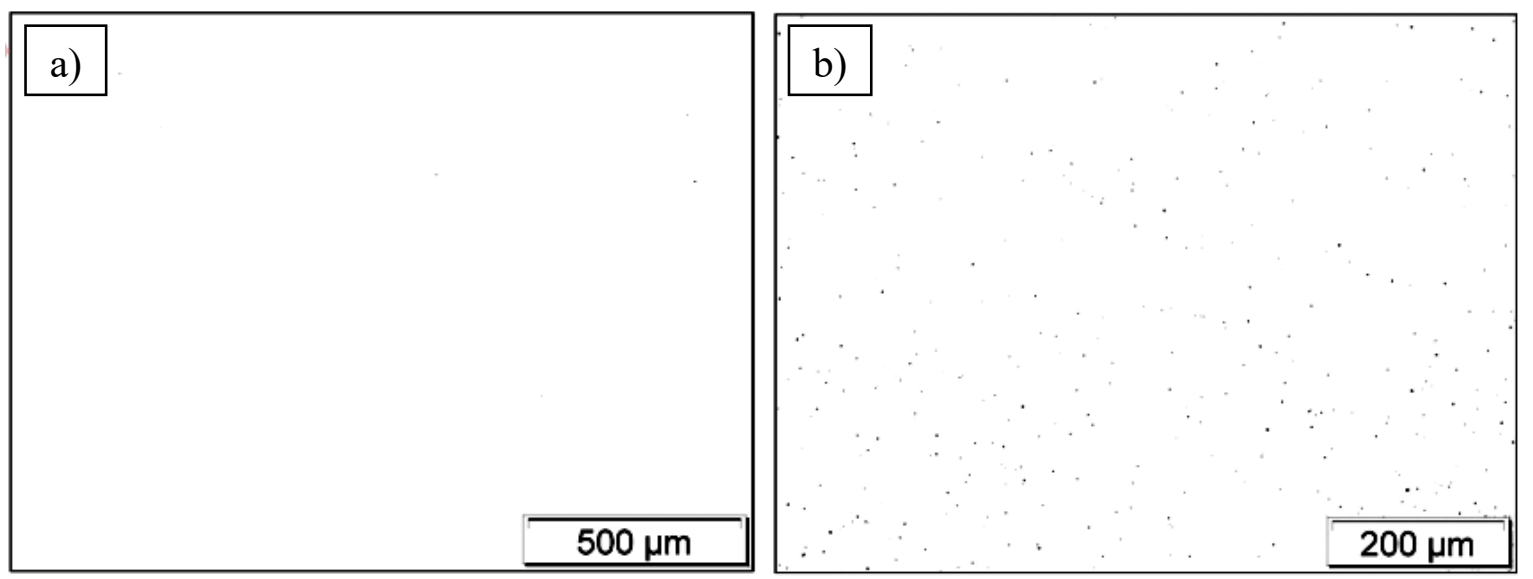

Fig. 1 Microstructure of polished samples SH 2-2 (A) and SV 1-1 (B) 
M. Sakoman, D. Ćorić,

T. Aleksandrov Fabijanić,

S. Kovačić
Tribological Properties of Coatings Applied on Near-Nano and Nanostructured WC-Co Hardmetals by Using Plasma-Assisted Chemical Vapour Deposition Technique

The sample was subsequently coated in order to investigate the influence of the $\eta$-phase on the scratch resistance and tribological performance of the deposited coating. The coating thickness results for all samples coated in two coating processes are summarized in Table 5. As there were two coating processes applied, the samples subjected to the same process showed similar coating thickness.

Table 5 Ball crater test results for all samples coated in two coating processes

\begin{tabular}{ccc}
\hline Sample & Average coating thickness $(\mu \mathrm{m})$ & Standard deviation $(\mu \mathrm{m})$ \\
\hline SV 1-1 & 1.94 & \pm 0.13 \\
SV 2-1 & 1.93 & \pm 0.14 \\
SH 2-1 & 2.09 & \pm 0.14 \\
SV 2-2 & 3.85 & \pm 0.15 \\
SH 2-2 & 3.90 & \pm 0.16 \\
SH 3-2 & 3.86 & \pm 0.15 \\
\hline
\end{tabular}

The thickness of the TiN coating is in the range from $1.94 \mu \mathrm{m}$ to $2.09 \mu \mathrm{m}$, while the thickness of the TiCN coating is in the range from $3.85 \mu \mathrm{m}$ to $3.90 \mu \mathrm{m}$. The repeatability of the coating thickness measured on different samples shows the quality of the performed PACVD technique. The hardness measurement results obtained for the substrate material and the nanoindentation measurements of the produced coatings are as expected for these types of base material and coatings, Figure 2. A total of five measurements was carried out on each sample. Although it is difficult to compare the Vickers macrohardness HV30 with the nanohardness HV0.005 due to the indentation size effect, from Figure 2 can be seen that the TiN coating proved to be harder than the substrate material. The purpose of this coating is to prevent the edge from building up, where the workpiece material sticks to the cutting edge. The built-up edge can have a negative effect on the surface finish of a workpiece, and also, when the built-up edge is dislodged, it pulls away a part of the coating and possibly the cutting edge [51].

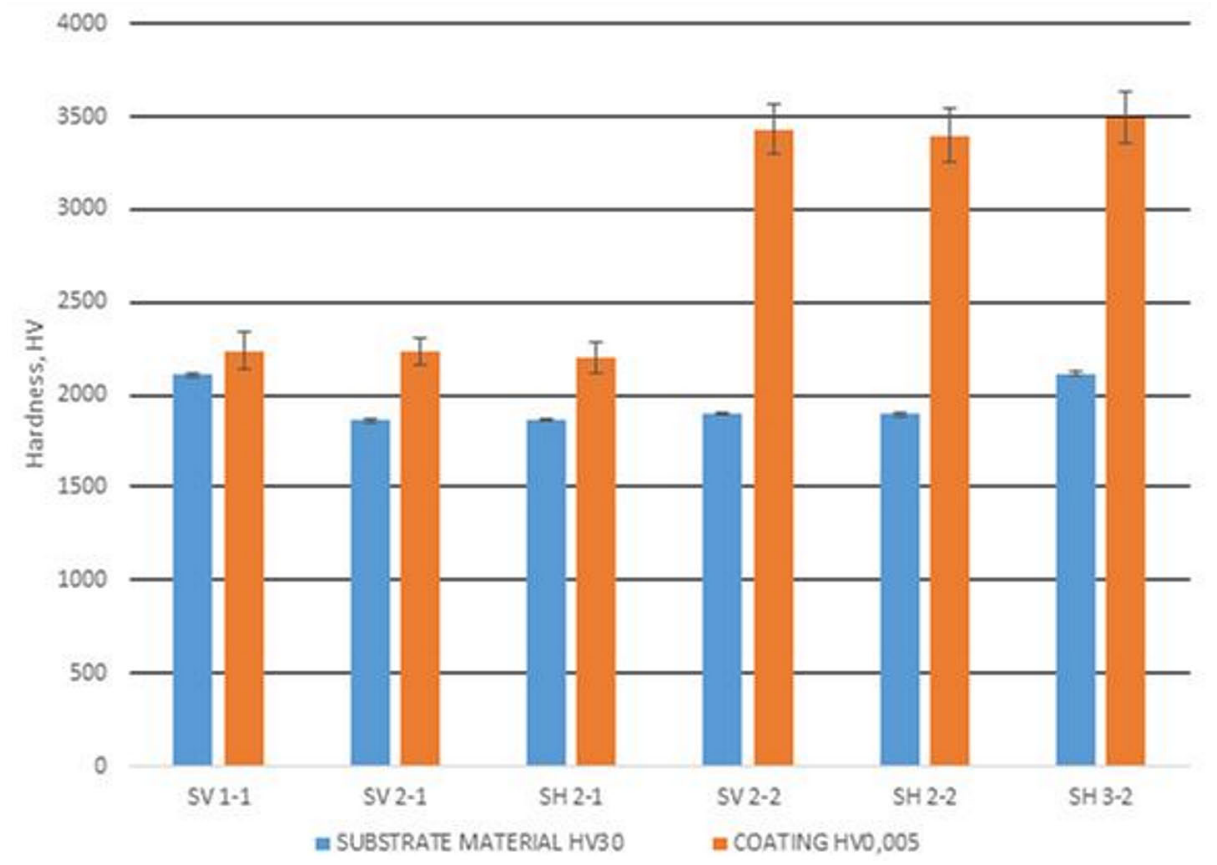

Fig. 2 Hardness values of the substrate material and coating 
The TiCN surface layer exhibits the hardness of almost $3500 \mathrm{HV} 0.005$, which is a significant surface hardness improvement compared to the substrate. The TiN and TiCN coating hardnesses are as expected [52]. The average critical normal loads are scattered when different substrate materials and coating systems are compared, Figure 3.

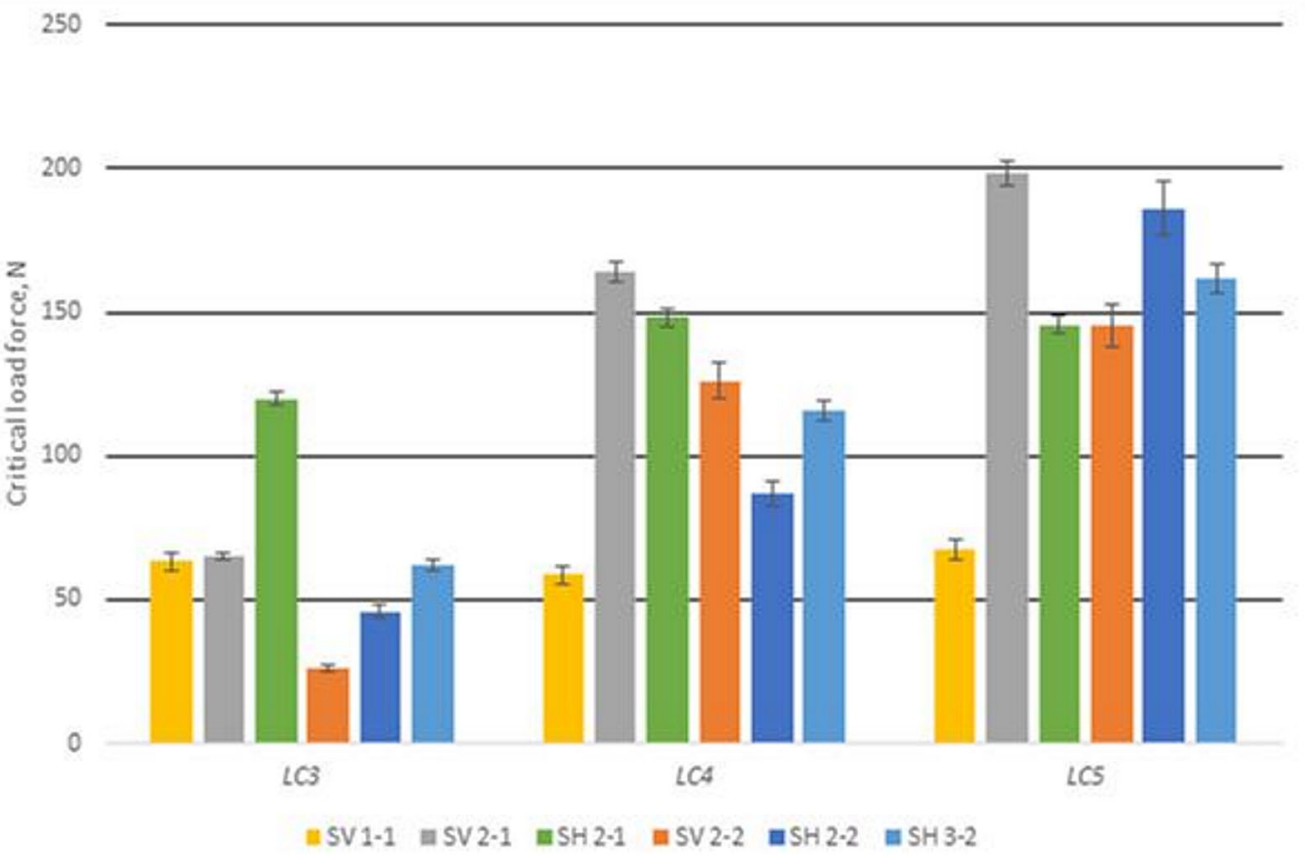

Fig. 3 Average critical normal loads for tested samples

Sample SV 1-1, coated with TiN, showed the worst coating adhesion, that is, the lowest force at which the coating spallation and worn-out coating occurs. Furthermore, the first spallation (outside), the first breakthrough and the totally worn-out coating occur at the same force. This can be attributed to two reasons. The first one might be the microstructural characteristics of the sample, such as lower density, a higher degree of porosity and cracks detected on the sample surface. The second reason is the size of the starting WC powder. Sample SV1-1 was consolidated from the $95 \mathrm{~nm}$ starting WC powder containing a higher addition of GGIs, which might be the reason for poorer coating adhesion. Nanopowders with the grain size $d_{\mathrm{BET}}$ less than $100 \mathrm{~nm}$ are very reactive and require different parameters of consolidation, such as compaction pressure, sintering temperature and time, carbon content, etc [53-55].

The highest force at which a worn-out coating occurs is found in sample SV 2-1 coated with TiN. High force values can be in correlation with the highest WC grain size, that is, less Co areas on the surface, and its lowest hardness, which serves as a support layer to the coating. For the same reason sample SV 2-2 coated with the TiCN coating has a relatively high critical normal load values. The coating adhesion decreases with an increase in coating thickness, so a slightly lower critical normal load can be attributed to this phenomenon.

In the case of sample SH 2-1 with the TiN coating, the first spallation (outside) occurred at a relatively high force. This can be attributed to the lowest amount of pores present after sintering this sample.

Sample SH 3-2 containing the $\eta$-phase exhibited good coating adhesion, in which phase the total delamination of the coating (LC5) occurred above $160 \mathrm{~N}$. Although it seems that the $\eta$-phase has a very little influence on the coating adhesion, it is highly unlikely that a tool containing this phase would have proper performances. 
M. Sakoman, D. Ćorić,

T. Aleksandrov Fabijanić,

S. Kovačić
Tribological Properties of Coatings Applied on Near-Nano and Nanostructured WC-Co Hardmetals by Using Plasma-Assisted Chemical Vapour Deposition Technique

In general, the used consolidation process did not contribute to the coating adhesion. Smaller grain sizes and higher hardness values achieved in the sintered and hot isostatic pressed samples showed better adhesion of the TiCN coating, while larger grain sizes and lower hardness achieved by the sintering in the case of the hydrogen sample showed better adhesion of the TiN coating.

In order to investigate the influence of the WC powder size on the coating adhesion a more detailed investigation is planned in the future.

The failures occurring during the scratch tests performed on the samples coated with a TiN layer are shown in Table 6.

Table 6 Critical normal loads of TiN coatings during scratch tests

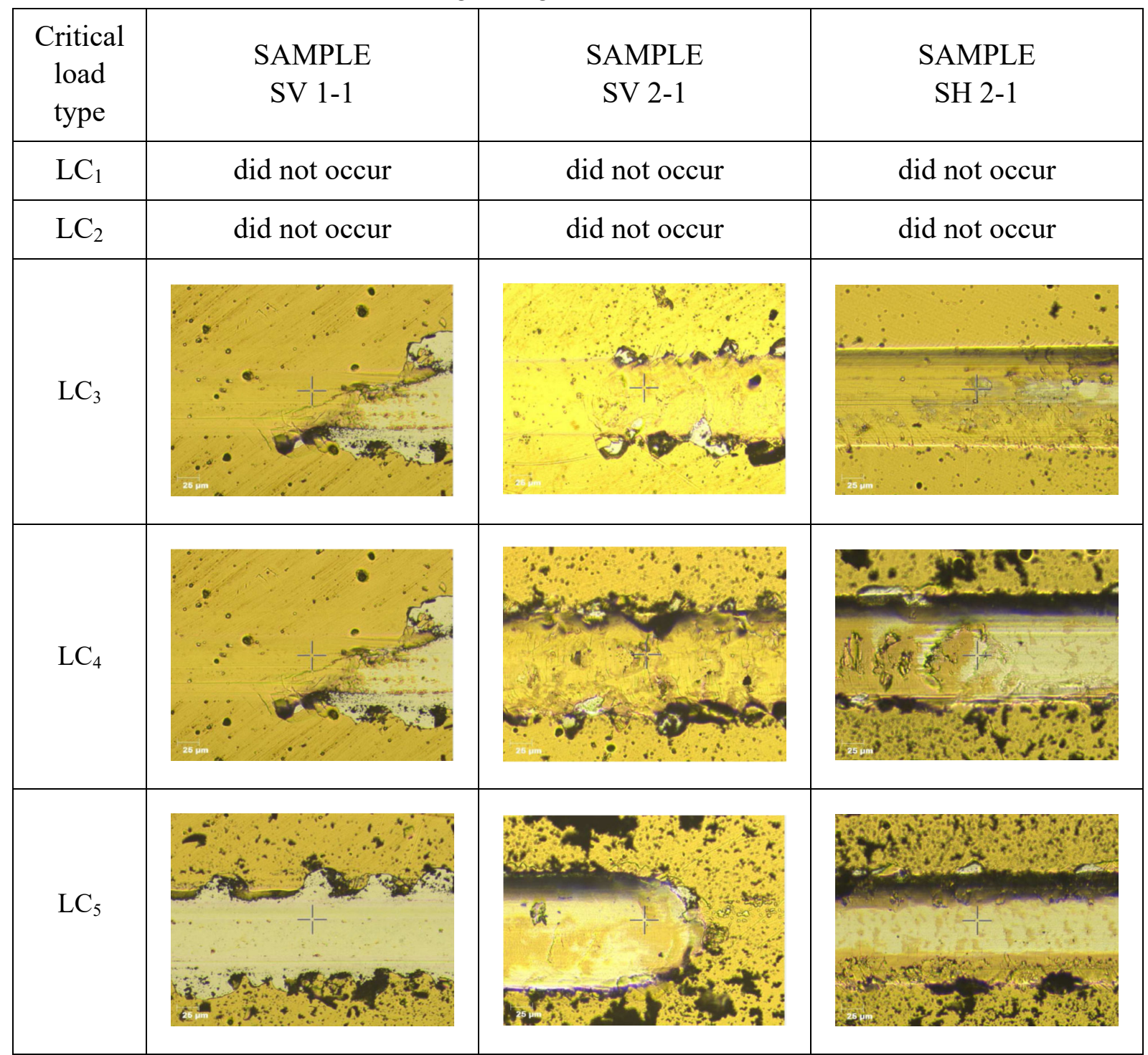

The critical normal load LC4, at which the first breakthrough of the coating occurs, when comparing samples SV 2-1 and SH 2-1 with the same coating thicknesses (around $2 \mu \mathrm{m})$ and the same Co content (9\% wt) but consolidated by different processes is practically the same. In the case of samples SV 2-1 and SH 2-1 the breakthrough occurs at around $150 \mathrm{~N}$, which means that relatively good coating adhesion has been achieved. The process of consolidation, sintering in hydrogen or sintering and hot isostatic pressing did not influence the coating adhesion. This supports the hypothesis that the TiN coating deposition was successfully carried out on near nanostructured hardmetals. 
Tribological Properties of Coatings Applied on Near-Nano and Nanostructured WC-Co Hardmetals by Using Plasma-Assisted Chemical Vapour Deposition Technique
M. Sakoman, D. Ćorić,

T. Aleksandrov Fabijanić,

S. Kovačić

The critical normal load in the case of sample SV 1-1 confirms the hypothesis that only tools produced by a full density process should be subsequently coated, as the porosity has major influence on coating adhesion. Also, a smaller WC grain size implies more Co areas, which has a negative effect on the coating adhesion [56].

Failures occurring during scratch tests carried out on the samples coated with TiCN layers are shown in Table 7.

Table 7 Critical normal loads for multilayer gradient TiN-TiCN coatings during scratch tests

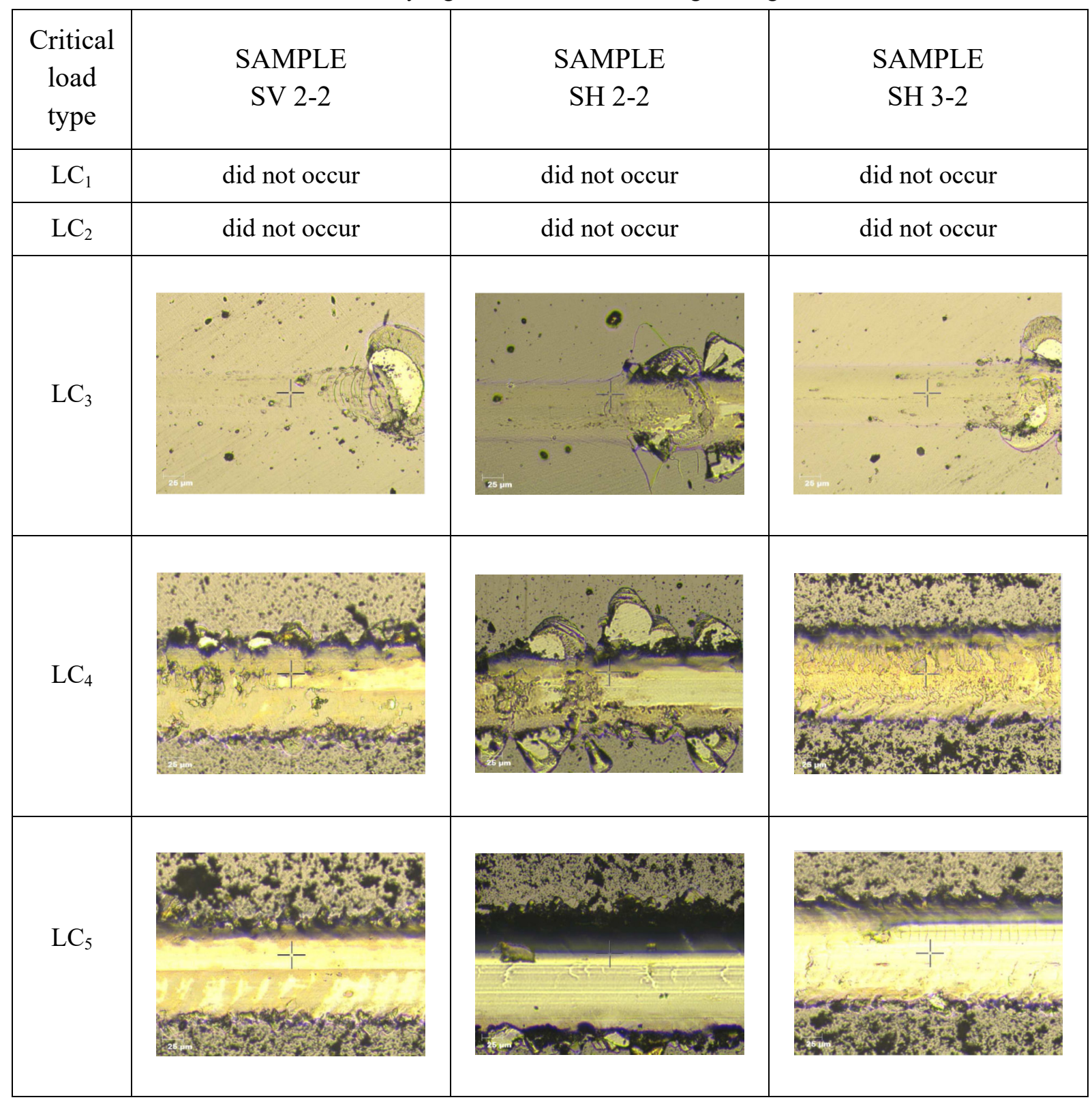

The substrate material does not show small delamination which occurs on the outer edges of the scratch marks at force LC3. As the force increases, lateral cracks occur along both sides of the scratch mark, however, without delamination or breaking (lateral breaking of the coating has a curved lateral character along the external edges of the grooves) and the substrate material is visible with the increasing load. This all indicates a good coating adhesion.

The ball-on-flat test showed the friction coefficients with respect to the test distance (Figure 4). 


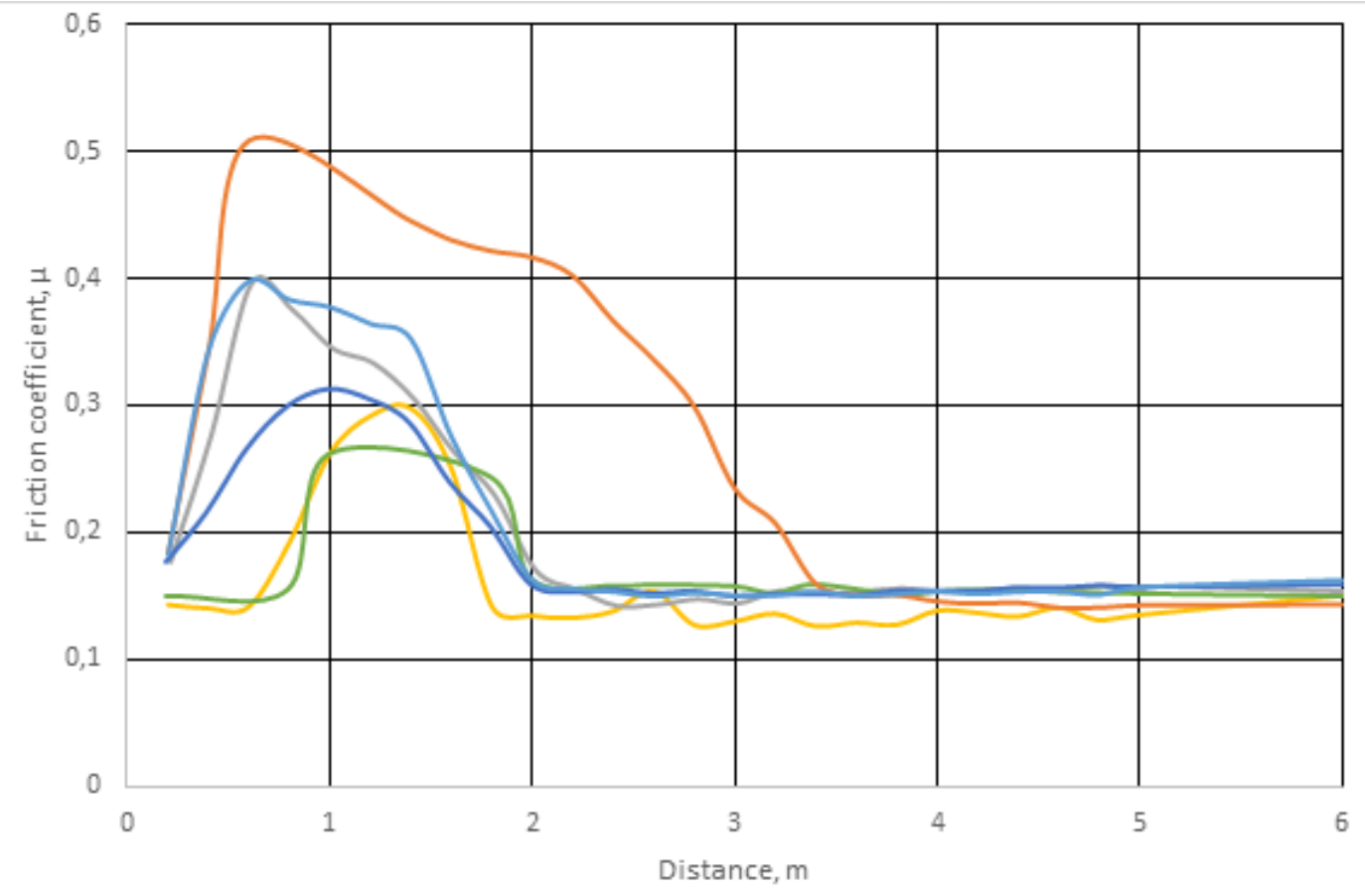

Fig. 4 Results of the ball-on-flat wear test

It is shown that the TiN layers have slightly lower friction coefficients in comparison to the TiCN coatings and are more appropriate for conditions where adhesion wear is a problem. The exception here is sample SV 1-1 with the TiN coating with a high degree of porosity and a smaller grain size of the starting WC powder. As the PACVD coating is formed evenly on the surface and follows the profile of the substrate material, a relatively high friction coefficient occurring in sample SV 1-1 can be attributed to the substrate porosity that influenced the mechanism of coating growth. The run-in period for samples SV 1-1 and SH 21 is a bit longer because the test started on the side of the ball which was previously used and was "polished" during testing. After some time, normal wear on the sample began to occur. As the samples were prepared evenly, possible small differences in roughness during the ballon-flat wear test are not related to the prior scratch adhesion results.

The worn-out volume obtained from the ball-on-flat wear test and the calculated wear factor are shown in Table 8.

Table 8 Standardized wear volume and the calculated wear factor

\begin{tabular}{cccc}
\hline Sample & Coating & Wear volume, $V\left(\mathrm{~mm}^{3}\right)$ & Wear factor, $K w\left(\mathrm{~mm}^{3} / \mathrm{Nm}\right)$ \\
\hline SV 1-1 & & 2.7933 & 2.7933 \\
SV 2-1 & TiN & 0.0529 & 0.0011 \\
SH 2-1 & & 0.0563 & 0.0011 \\
\hline SV 2-2 & & 0.1470 & 0.0029 \\
SH 2-2 & TiN-TiCN & 0.0941 & 0.0019 \\
SH 3-2 & & 0.0568 & 0.0011 \\
\hline
\end{tabular}


The wear volume is the highest in sample SV 1-1 coated with TiN, which is in correlation with the previous tests showing the negative effects of a porous product. All other samples have a similar standardized wear volume loss. Nevertheless, it is important to emphasize that the volume loss is fairly low and shows a trend in wear. For future research the application of a higher force and a longer path distance is recommended.

\section{Conclusions}

The conducted study confirmed the influence of the microstructure of hardmetals and two coating types on coating adhesion, friction coefficients and volume loss. The following conclusions can be made:

- Surface porosity and a small WC grain size significantly reduced coating adhesion and increased volume loss by sliding wear;

- The used consolidation process did not contribute to coating adhesion. Smaller grain sizes and higher hardness values in the samples consolidated by sintering and hot isostatic pressing showed better adhesion of the TiCN coating, while larger grain sizes and lower hardness achieved by the sintering in the hydrogen sample showed better adhesion of the TiN coating.

- The $\eta$ phase in sample SH 3-2 had very little influence on the coating adhesion of the multilayer TiCN coating.

Consequently, PACVD coatings deposited on nanostructured hardmetals can have excellent coating adhesion and low wear volume loss, but further improvements are possible. The Co content in the surface area where the coating is to be deposited should be reduced. For a more detailed analysis, measurements of residual stresses would be recommended. This is the first step in the development of a new innovative procedure for PACVD coatings on nanostructured hardmetals. According to this study, nanostructured hardmetals showed a good potential as substrate materials for PACVD coatings.

\section{Acknowledgment}

This study is partially supported by the Croatian Science Foundation under the Project Number UIP-2017-05-6538 Nanostructured hardmetals - New challenges for Powder Metallurgy.

\section{REFERENCES}

[1] Z. Z. Fang, X. Wang, T. Ryu, K. S. Hwang, H.Y. Sohn: Synthesis, sintering, and mechanical properties of nanocrystalline cemented tungsten carbide - A review, International Journal of Refractory Metals \& Hard Materials, (2008), Volume 27, 288-299. https://doi.org/10.1016/j.ijrmhm.2008.07.011

[2] V. Bonache, M.D.Salvador, D.Busquets, P.Burguete, E.Martinez, F.Sapina, E.Sanchez: Synthesisand processing of nanocrystalline tungsten carbide: Toward cemented carbides with optimal mechanical properties, International Journal of Refractory Metals and Hard Materials, (2011), Volume 29, 78-84. https://doi.org/10.1016/j.ijrmhm.2010.08.003

[3] T. A. Fabijanić, Ž. Alar, D. Ćorić: Influence of consolidation process and sintering temperature on microstructure and mechanical properties of near-nano and nanostructured WC-Co Cemented Carbides, International Journal of Refractory Metals and Hard Materials, (2015), Volume 54, 82-89. https://doi.org/10.1016/j.ijrmhm.2015.07.017

[4] Ö. Baran, E. E. Sukuroglu, İ. Efeoglu \& Y. Totik: The investigation of adhesion and fatigue properties of TiN/TaN multilayer coatings, Journal of Adhesion Science and Technology, (2016), Volume 30, Issue 20, 2188-2200. https://doi.org/10.1080/01694243.2016.1176662

[5] H. Kenneth, M. Allan: Coatings Tribology: Properties, Mechanisms, Techniques and Applications in Surface Engineering, Elsevier Science, 2009. 
M. Sakoman, D. Ćorić,

T. Aleksandrov Fabijanić,

S. Kovačić
Tribological Properties of Coatings Applied on Near-Nano and Nanostructured WC-Co Hardmetals by Using Plasma-Assisted Chemical Vapour Deposition Technique

[6] J. Takadoum, H. H. Bennani: Influence of substrate roughness and coating thickness on adhesion, friction and wear of TiN films, Surface Coatings Technology, (1997), Volume 96, 272-282. https://doi.org/10.1016/s0257-8972(97)00182-5

[7] C. W. Moura e Silva, E. Alves, a. R. Ramos, C. S. Sandu, a. Cavaleiro: Adhesion failures on hard coatings induced by interface anomalies, Vacuum, (2009), Volume 83, 1213-1217. https://doi.org/10.1016/j.vacuum.2009.03.010

[8] A. Formisano, F. Capece Minutolo, A. Caraviello, L. Carrino, M. Durante, A. Langella: Influence of EtaPhase on Wear Behavior of WC-Co Carbides, Advances in Tribology, (2016), Volume 2016, Article ID: 5063274. https://doi.org/10.1155/2016/5063274

[9] L. Åkesson: An Experimental and Thermodynamic Study of the Co-W-C System in the Temperature Range 1470-1700 K, (1983), Science of Hard Materials, 71-82.

https://doi.org/10.1007/978-1-4684-4319-6_4

[10] M. N. Haller: Cemented carbides: metallographic techniques and microstructures, ASM Handbook, Volume 9 (2004), 513-545.

[11] V. K. Sarin: Morphology of eta phase in cemented WC-Co alloys, Modern Development in Powder Metallurgy, (1977), Volume 10, 553-565.

[12] K. H. Cho, J. W. Lee, and I. S. Chung: A study on the formation of anomalous large WC grain and the eta phase, Materials Science and Engineering A, (1996), Volume 209, 298-301. https://doi.org/10.1016/0921-5093(95)10104-7

[13] A. F. Guillermet: Thermodynamic properties of the Co-W-C system, Metallurgical Transactions A, (1989), Volume 20, 935-956. https://doi.org/10.1007/bf02651660

[14] C. B. Pollock, H. H. Stadelmaier: The eta carbides in the Fe-W-C and Co-W-C systems, Metallurgical Transactions, (1970), Volume 1, 767-770.

[15] O. Eso, Z. Z. Fang, and A. Griffo: Kinetics of cobalt gradient formation during the liquid phase sintering of functionally graded WC-Co, International Journal of Refractory Metals and Hard Materials, Volume 25 (2007), 286-292. https://doi.org/10.1016/j.ijrmhm.2006.07.002

[16] G.-H. Lee, S. Kang: Sintering of nano-sized WC-Co powders produced by a gas reduction-carburation process, Journal of Alloys and Compounds, (2006), Volume 419, 281-289.

https://doi.org/10.1016/j.jallcom.2005.09.060

[17] P. Yan, Y.M. Rong, G. Wang: The effect of cutting fluids applied in metal cutting process, Proceedings of the Institution of Mechanical Engineers, Part B: Journal of Engineering Manufacture, (2016), 230(1), 19-37. https://doi.org/10.1177/0954405415590993

[18] M. Azadi, A. S. Rouhaghdam, S. Ahangarani, H.H. Mofidi: Mechanical behavior of TiN/TiC multilayer coatings fabricated by plasma assisted chemical vapor deposition on AISI H13 hot work tool steel, Surface and Coatings Technology, (2014), Volume 245, 156-166.

https://doi.org/10.1016/j.surfcoat.2014.02.055

[19] M. Nordin, M. Larsson, S. Hogmark: Wear resistance of multilayered PVD TiN/TaN on HSS. Surface and Coatings Technology, (1999), Volume 120, 528-534. https://doi.org/10.1016/s0257-8972(99)00493-4

[20] M. Nordin, F. Ericson: Growth characteristics of multilayered physical vapour deposited TiN/TaNx on high speed steel substrate, Thin Solid Films, (2001), Volume 385, 174-181. https://doi.org/10.1016/s0040-6090(00)01880-0

[21] Ö. Baran, E. E. Sukuroglu, İ. Efeoglu, Y. Totik: The investigation of adhesion and fatigue properties of TiN/TaN multilayer coatings, Journal of Adhesion Science and Technology, (2016), Volume 30, 21882200. https://doi.org/10.1080/01694243.2016.1176662

[22] J. An, QJ. Zhang: Structure, morphology and nanoindentation behavior of multilayered TiN/TaN coatings, Surface Coatings Technology, (2005), Volume 200, 2451-2458. https://doi.org/10.1016/j.surfcoat.2005.02.204

[23] O. Knotek, F. Löffler, G. Krämer: Multicomponent and multilayer physically vapour deposited coatings for cutting tools, Surface Coatings Technology, (1992), Volume 54, 241-248. https://doi.org/10.1016/s0257-8972(09)90057-3

[24] M. Finot, Y.L. Shen, S. Suresh: Micromechanical modeling of damage in particle-reinforced composites, Proceedings of the 1994 international mechanical engineering congress and exposition, (1994), Volume $185,163-166$. 
Tribological Properties of Coatings Applied on

Near-Nano and Nanostructured WC-Co Hardmetals by Using

Plasma-Assisted Chemical Vapour Deposition Technique
M. Sakoman, D. Ćorić,

T. Aleksandrov Fabijanić,

S. Kovačić

[25] T.I. Selinder, M.E. Sjöstrand, M. Nordin: Performance of PVD TiN/TaN and TiN/NbN superlattice coated cemented carbide tools in stainless steel machining, Surface Coatings Technology, (1998), Volume 105, 51-55. https://doi.org/10.1016/s0257-8972(98)00446-0

[26] M. Larsson, P. Hollman, P. Hedenqvist: Deposition and microstructure of PVD TiN-NbN multilayered coatings by combined reactive electron beam evaporation and DC sputtering, Surface Coatings Technology, (1996), Volume 86, 351-356. https://doi.org/10.1016/s0257-8972(96)03026-5

[27] H.C. Barshilia, K.S. Rajam: Structure and properties of reactive DC magnetron sputtered TiN/NbN hard superlattices, Surface Coatings Technology, (2004), Volume 183, 174-183. https://doi.org/10.1016/j.surfcoat.2003.09.070

[28] K.L. Rutherford, P.W. Hatto, C. Davies: Abrasive wear resistance of TiN/NbN multi-layers: measurement and neural network modelling, Surface Coatings Technology, (1996), Volume 86, 472-479. https://doi.org/10.1016/s0257-8972(96)02956-8

[29] V.N. Zhitomirsky, I. Grimberg, L. Rapoport: Vacuum arc deposition of TiN, NbN and TiN/NbN multilayer coatings, Surface Coatings Technology, (1999), Volume 120, 219-225. https://doi.org/10.1016/s0257-8972(99)00382-5

[30] M. Setoyama, A. Nakayama, M. Tanaka: Formation of cubic-A1N in TiN/A1N superlattice, Surface Coatings Technology, (1996), Volume 86 225-230. https://doi.org/10.1016/s0257-8972(96)03033-2

[31] M.S. Wong, G.Y. Hsiao, SY. Yang: Preparation and characterization of AlN/ZrN and AlN/TiN nanolaminate coatings, Surface Coatings Technology, Volume 133 (2000), 160-165. https://doi.org/10.1016/s0257-8972(00)00958-0

[32] P.E. Hovsepian, D.B. Lewis, W.D. Münz: Recent progress in large scale manufacturing of multilayer/superlattice hard coatings, Surface Coatings Technology, (2000), Volume 133, 166-175. https://doi.org/10.1016/s0257-8972(00)00959-2

[33] P. Yashar, X. Chu, S.A. Barnett: Stabilization of cubic CrN [sub 0.6] in CrN [sub 0.6]/TiN superlattices, Applied Physics Letters, (1998), Volume 72, 987-989.

[34] Y. Zhou, R. Asaki, W.H. Soe: Hardness anomaly, plastic deformation work and fretting wear properties of polycrystalline TiN/CrN multilayers, Wear, (1999), Volume 236, 159-164. https://doi.org/10.1016/s0043-1648(99)00272-0

[35] S.Y. Lee, G.S. Kim, J.G. Hahn: Effect of the Cr content on the mechanical properties of nanostructured TiN/CrN coatings, Surface Coatings Technology, (2004), Volume 177, 426-433. https://doi.org/10.1016/j.surfcoat.2003.09.020

[36] M. Braic, M. Balaceanu, A. Vladescu: TiN/ZrN heterostructures deposition and characterization, Surface Coatings Technology, (2006), Volume 200, 6505-6510. https://doi.org/10.1016/j.surfcoat.2005.11.057

[37] A. Rizzo, MA. Signore, M. Penza M: RF sputtering deposition of alternate TiN/ZrN multilayer hard coatings, Thin Solid Films, (2006), Volume 515, 500-504. https://doi.org/10.1016/j.tsf.2005.12.279

[38] A. Rizzo, MA. Signore, MFD. Riccardis: Influence of growth rate on the structural and morphological properties of TiN, ZrN and TiN/ZrN multilayers, Thin Solid Films, (2007), Volume 515, 6665-6671. https://doi.org/10.1016/j.tsf.2007.01.001

[39] X.M. Xu, J. Wang, J. An: Effect of modulation structure on the growth behavior and mechanical properties of TiN/ZrN multilayers, Surface Coatings Technology, (2007), Volume 201, 5582-5586. https://doi.org/10.1016/j.surfcoat.2006.07.132

[40] X.M. Xu, J. Wang, Q.Y. Zhang: Oxidation behavior of TiN/ZrN multilayers annealed in air, Thin Solid Films, Volume 516 (2008), 1025-1028. https://doi.org/10.1016/j.tsf.2007.07.007

[41] S. Ulrich, C. Ziebert, M. Stüber: Correlation between constitution, properties and machining performance of TiN/ZrN multilayers, Surface Coatings Technology, (2004), Volume 188, 331-337. https://doi.org/10.1016/j.surfcoat.2004.08.056

[42] C.J. Tavares, L. Rebouta, B. Almeida: Deposition and characterization of multilayered TiN/ZrN coatings, Thin Solid Films, (1998), Volume 317, 124-128. https://doi.org/10.1016/s0040-6090(97)00607-X

[43] Y. Wei, C. Gong: Effects of pulsed bias duty ratio on microstructure and mechanical properties of TiN/TiAlN multilayer coatings, Applied Surface Science, (2011), Volume 257, 7881-7886. https://doi.org/10.1016/j.apsusc.2011.04.066

[44] K. Chu, Y.G. Shen: Mechanical and tribological properties of nanostructured TiN/TiBN multilayer films, Wear, (2008), Volume 256, 516-524. https://doi.org/10.1016/j.wear.2007.11.021 
M. Sakoman, D. Ćorić,

T. Aleksandrov Fabijanić,

S. Kovačić
Tribological Properties of Coatings Applied on Near-Nano and Nanostructured WC-Co Hardmetals by Using Plasma-Assisted Chemical Vapour Deposition Technique

[45] D.G. Liu, J.P. Tu, C.D. Gu: Tribological and mechanical behaviors of TiN/CNx multilayer films deposited by magnetron sputtering, Thin Solid Films, (2011), Volume 519, 48424848. https://doi.org/10.1016/j.tsf.2011.01.039

[46] M. Nordin, R. Sundström, T.I. Selinder: Wear and failure mechanisms of multilayered PVD TiN/TaN coated tools when milling austenitic stainless steel, Surface Coatings Technology, (2000), Volume 519, 240-246. https://doi.org/10.1016/s0257-8972(00)00933-6

[47] M. Nordin, M. Larsson, S. Hogmark: Mechanical and tribological properties of multilayered PVD TiN/CrN, TiN/MoN, TiN/NbN and TiN/TaN coatings on cemented carbide, Surface Coatings Technology, (1998), Volume 106, 234-241. https://doi.org/10.1016/s0257-8972(98)00544-1

[48] X. Junhua, L. Geyang, G. Mingyuan: The microstructure and mechanical properties of TaN/TiN and TaWN/TiN superlattice films, Thin Solid Films, (2000), Volume 370, 45-49. https://doi.org/10.1016/s0040-6090(00)00940-8

[49] T. A. Fabijanić, S. Jakovljević, M. Franz, I. Jeren: Influence of Grain Growth Inhibitors and Powder Size on the Properties of Ultrafine and Nanostructured Cemented Carbides Sintered in Hydrogen, Metals, (2016), Volume 6, Article number: 198. https://doi.org/10.3390/met6090198

[50] T. A. Fabijanić, Ž. Alar, D. Ćorić: Influence of Consolidation Process and Sintering Temperature on Microstructure and Mechanical properties of Near Nano- and Nanostructured WC-Co Cemented Carbides, International Journal of Refractory Metals and Hard Materials, (2016), Volume 54, 82-89. https://doi.org/10.1016/j.ijrmhm.2015.07.017

[51] J. Kümmel, K. Poser, F. Zanger, J. Michna, V. Schulze: Surface Layer States of Worn Uncoated and TiNCoated WC/Co-Cemented Carbide Cutting Tools after Dry Plain Turning of Carbon Steel, Hindawi Publishing Corporation, Advances in Tribology, (2013), Volume 2013, Article ID: 519686. https://doi.org/10.1155/2013/519686

[52] T. A. Fabijanić, D. Ćorić, M. Š. Musa, M. Sakoman: Vickers Indentation Fracture Toughness of NearNano and Nanostructured WC-Co Cemented Carbides, Metals, (2017), Volume 7. Article number: 143. https://doi.org/10.3390/met7040143

[53] X. Wang, Z. Z. Fang, H. Y. Sohn: Grain growth during the early stage of sintering of nanosized WC-Co powder, International Journal of Refractory Metals \& Hard Materials, (2008), Volume 26, 232-241. https://doi.org/10.1016/j.ijrmhm.2007.04.006

[54] Z.G. Ban, L.L. Shaw: Synthesis and processing of nanostructured WC-Co materials, Journal of Materials Science, (2002), Volume 37, 3397-3403.

[55] Z.Z. Fang, J.W. Eason: Study of nanostructured WC-Co composites, International Journal of Refractory Metals \& Hard Materials, (1995), Volume 13, 297-303. https://doi.org/10.1016/0263-4368(95)92675-a

[56] M.A. Salete, A. Wendell, J. Adilson: Improvement of coating adhesion on cemented carbide tools by plasma etching, Journal of Brazilian Society of Mechanical Sciences and Engineering, (2017), Volume $29,846-856$

Submitted: $\quad$ 13.9.2019

Accepted: $\quad$ 16.12.2019
Matija Sakoman

Danko Ćorić

Tamara Aleksandrov Fabijanić

Saša Kovačić

Faculty of Mechanical Engineering and

Naval Architecture, Zagreb 